An ESRC Research Group

\title{
The case for cross-disciplinary social science research on poverty, inequality and well-being
}

\author{
GPRG-WPS-001
}

\author{
David Hulme and John Toye
}

\section{Global Poverty Research Group}

Website: http://www.gprg.org/

The support of the Economic and Social Research Council (ESRC) is gratefully acknowledged. The work was part of the programme of the ESRC Global Poverty Research Group. 


\title{
THE CASE FOR CROSS-DISCIPLINARY SOCIAL SCIENCE RESEARCH ON POVERTY, INEQUALITY AND WELL-BEING
}

\author{
David Hulme and John Toye
}

\section{GPRG-WPS-001}

\begin{abstract}
Arguments for cross-disciplinary research in development studies have been applied recently to work on poverty, inequality and well-being. However, much research on these issues remains fragmented and, in particular, the intellectual barrier between economics and the other social science subjects continues to be powerful. In this paper, we review the prospects for cross-disciplinary research (both multidisciplinary and interdisciplinary); and, examine the ways in which forms of being 'disciplined', and the linkages between disciplines and professions, constrains such research. We also introduce the papers in this collection and explain their relationship to the quest for crossdisciplinary research on poverty issues. Our conclusion is that cross-discipline working should be promoted and that both interdisciplinary and multidisciplinary approaches can benefit research on poverty and well-being, provided that their specific merits and demerits are evaluated in relation to the research task in hand.
\end{abstract}

Keywords: poverty, well-being, inequality, methods, theory, multidisciplinarity, interdisciplinarity

David Hulme is Professor of Development Studies and Director of the Chronic Poverty Research Centre at the Institute for Development Policy and Management at the University of Manchester. John Toye is a Senior Research Associate of Queen Elizabeth House, University of Oxford. The authors would like to thank colleagues in the Global Poverty Research Group at the Universities of Manchester and Oxford for discussions on these subjects and comments on the draft paper and David Clark for research assistance. The constructive criticisms of the original draft by an anonymous referee were extremely helpful. The research was supported by the ESRC grant to the Global Poverty Research Group (grant no. M571255001). 
"If we ask academics why poor people are poor... different disciplines will answer... in their own unique ways; each with certain kinds of data, certain methods, certain habits of thinking... in most substantive areas [of the social sciences] there is what to outsiders seems like an amazing lack of reciprocal knowledge”. (Abbott 2001:142)

\section{Introduction}

At the end of the nineteenth century, partly as a response to the ebbing of Christian religious belief, a new secular humanitarianism increasingly coloured British public opinion. It focused attention on a social phenomenon that had previously been accepted as natural and inevitable, if unfortunate - the poverty of those in the lower ranks of society. This new humanitarian feeling of concern for the poor produced its own scientific analogue. It motivated a new, positivist science of society, which went well beyond the informational eclecticism and the political partisanship of Engels' ground breaking Condition of the Working Class in England (1845). People now believed that the compassion of concern for the poor should be tempered by a sense of proportion, and that this could be best provided by thorough and intelligent enquiry into numerical information. The aim of social research was to give a sober statistical account of the extent and nature of poverty, and thus to provide the evidence base for a properly measured social policy response (Himmelfarb 1991:3-18). Key exponents of this approach were Charles Booth (1892) in London and Seebohm Rowntree (1901) in York. 
During the twentieth century, however, research on poverty became increasingly specialized, as the methods of study were gradually refined to make them more penetrating and sophisticated. However, the benefits of specialization brought with them various costs, most particularly an erosion of the overall coherence of the concept of poverty. Those working in different subject areas of social science, such as economics, anthropology, human geography, sociology and political studies, have undoubtedly done much illuminating research into many aspects and dimensions of poverty. However, communications between researchers in different areas have been remarkable largely for their absence: this has particularly been the case between economics and the other social sciences. Throughout the 1990s, while economists have attempted to define and measure global poverty with increasing precision, researchers taking an anthropological perspective have advised that '...poverty is a myth, a construct and the invention of a particular civilization' (Rahnema 1992:158).

There are general reasons, then, arising from the splintering of theoretical and applied knowledge, for believing that the adoption of a more cross-disciplinary research strategy would strengthen the coherence and social relevance of the results that researchers generate. Furthermore, there are reasons to believe that the study of well-being and poverty is a particularly appropriate subject for cross-discipline research. John Knight (1991:26) put the point well from the economist's perspective.

"If we are ultimately concerned with things like poverty, hunger, inequality, 'people's capabilities to be and do things', and so on, and with 
policies to make improvements, then we must recognise that economics is interdependent and cannot be isolated."

Such recognition leads in the direction of cross-disciplinary research, defined as any analysis or policy recommendation based on questions, concepts or methods of more than one academic discipline. Yet as long as many economists still claim that economics can be 'contaminated' by the 'softer' disciplines of other social sciences, it will require considerable energy, intellectual courage and integrity to design and implement a crossdisciplinary research strategy on poverty and well-being.

When we speak of social science, we have a particular set of subjects in mind, and it is useful at the outset to specify our coverage. Our focus is on economics, sociology, anthropology, politics and human geography. Much of our discussion will contrast economics with sociology, anthropology, politics and human geography (henceforth SAPG) $)^{1}$. To two potentially important subject areas we pay limited attention. The first is psychology, often formally classified as a science, rather than a social science, in UK universities. Psychology, and even social psychology, has less frequently engaged with development studies or the analysis of well-being, poverty and inequality in the context of developing countries. ${ }^{2}$ However, very recently, economists and social psychologists have begun to work together and in future psychology may well demand greater attention. The second is philosophy. Every social science draws on philosophy, in one

\footnotetext{
${ }^{1}$ This is Jackson's (2002) SAP with human geography added. We have added human geography as in the UK, parts of Northern Europe and USA geographers of development studies have played an increasingly active role in research on poverty, inequality and well-being over the last 10-15 years.

2 A notable exception is the World Health Organisation's WHO-QOL project, which developed and applied an instrument for assessing the quality of life in one hundred different fieldwork sites. The abridged version of this measure, which draws on work in 32 localities, covers more second and third world countries than first world countries (see WHOQOL Group, 1998, table 2).
} 
way or another, in search of answers to its specific ontological, epistemological, methodological and conceptual problems. Yet philosophy can provide them with neither a Platonic method of acquiring knowledge infallibly nor an Aristotelian map of all branches of knowledge. In this introduction (and in the articles that follow), reference is made to the contributions of social scientists who have drawn on philosophy (especially Amartya Sen) ${ }^{3}$ and philosophers who have ventured into social science (such as Martha Nussbaum). The large and growing body of work on well-being produced by philosophers is not explored, however. ${ }^{4}$

A generation ago, Michael Lipton (1970) made the classic statement, from the economic viewpoint, of the case for a cross-disciplinary dimension in poverty research. Yet the arguments of 30 years ago may not be persuasive today, and may be in need of revision in the light of recent intellectual developments. With this in mind, we re-assess the case for cross-discipline research on poverty and well-being, to see how much validity it retains and where it needs to be supplemented. In the course of this re-assessment, we introduce some relevant key ideas from the cross-disciplinary collection of papers that follows

The next section considers both the reasons why cross-discipline research is essential for future investigation of poverty and well-being, and the incentives that have favoured ever

\footnotetext{
${ }^{3}$ Also see the work of researchers focusing on development ethics such as Crocker (1992), Gasper (2004), Goulet (1971; 1995), Nussbaum (2002), Qizilbash (1996) and Clark (2002a,b), inter alia. There is also a vast literature in mainstream philosophy on the subject of well-being. One of the most notable contributions by a contemporary philosopher is Jim Griffin's (1986) book, Well-Being: It's Meaning, Measurement and Moral Importance. For further references to the well-being literature see Clark (2002b).

${ }^{4}$ Interestingly, Clark (2002b) proposes that an 'empirical philosophy' of well-being might advance the understanding of well-being by detaching from social science disciplines and engaging with the views and experiences of 'ordinary people' in a logically rigorous manner.
} 
more specialised single-subject research: incentives that at times have generated selfjustifying subject stereotypes. The paper then argues in section 3 against the application of dichotomous stereotypes to economics, on the one hand, and the SAPG or "noneconomics' subjects on the other. ${ }^{5}$ The commonly applied dichotomies are objective versus subjective, quantitative versus qualitative, and positivist versus post-positivist. In section 4, we explore the meaning of an intellectual discipline and suggest that it is the normative practice of a 'knowledge community', and that it shapes both cohesion within social science subjects and the degree of affinity between researchers in different subject areas. We decompose cross-disciplinary research by distinguishing between multidisciplinary and interdisciplinary approaches. Section 5 makes a qualified defence of those researchers, and particularly economists, who 'trespass' beyond the assumed boundaries of their disciplines against charges of intellectual imperialism. In section 6 , we examine the ways in which different disciplines do and do not relate to practising professions. This has profound implications for cross-disciplinarity. The conclusion suggests ways in which the benefits of cross-discipline research can be realized.

The paper draws on the existing literature and the cross-disciplinary seminars mounted by the ESRC's Global Poverty Research Group (GPRG) at the universities of Manchester and Oxford. In addition, it makes use of the results of two types of empirical analysis. Content analysis and citation analysis studies, applied to articles in academic journals by

\footnotetext{
${ }^{5}$ The term 'non-economics' is sometimes used to refer to the social sciences other than economics. However, such a label may not be helpful as many 'non economists' point out that their research is focused on the social, political and cultural understanding of economic issues such as markets, financial institutions, access to resources and accumulation.
} 
economists and other social scientists, are used to give an account of how social sciences differ with respect to quantification, and how they communicate with each other.

\section{Why is cross-discipline collaboration needed and why doesn't it happen?}

How does the need for cross-discipline collaboration arise? One reason is that the individual disciplines have, over the years, become increasingly differentiated and refined. In the very process of differentiation and refinement, they have also developed blind spots and methodological limitations that arise from their high degree of specialisation. Within a discipline, its basic working assumptions are accepted uncritically, because they are part of the consensus around its research paradigm. Sophistication has been purchased at the cost of an excessive narrowing of focus. For example, the bulk of econometric research on poverty still uses a concept of income/consumption poverty, even though many of the econometricians conducting the work agree that poverty has to be understood as a multidimensional phenomena and that 'non monetary' measures are feasible (see below).

Similarly established paradigms shape the work of sociologists, social anthropologists, political scientists and others who have refined their own conceptual vocabularies, and developed preferred strategies of investigation that are highly specific to themselves. Sociologists and human geographers may have documented fascinating life histories of poor people that reveal important processes (e.g. Bourdieu et al 1999; Hulme 2004), but it is difficult (econometricians would say impossible) to use these to test hypotheses or to 
make generalisations when ' $\mathrm{n}=1$ ' or the sampling procedure cannot explain the position of respondents in the wider population. New efforts are now required in collaboration among disciplines that are used to study well being, poverty and inequality, to deepen understanding and contribute to more effective policy. Indeed, the recent shift from analysing poverty (deprivation) to well-being favours cross-disciplinary approaches that can capture all the different aspects of well-being.

This insight is by no means new, but it does seem to be something that has to be repeated. It is important to recall that Charles Booth's foundational studies of poverty in late nineteenth century London were based on a mixture of methods of investigation and a multidimensional concept of poverty. Booth believed that "the statistical method was needed to give bearings to the results of personal observation, and personal observation to give life to statistics". ${ }^{6}$ He never attempted to define the poor solely as those whose consumption fell below a monetary poverty line. His investigators used figures of apparent weekly earnings as one criterion among several, including information on health status and school attendance recorded by authoritative local observers, to assign households to a number of different social classes. ${ }^{7}$ This made it possible to triangulate findings and consider the linkages between different dimensions of poverty.

Later work on poverty has tended to be more methodologically bifurcated. Rowntree, for example, developed much more sharply than Booth the idea of a "primary poverty line" based on the income required for a diet providing bare physical efficiency. He also

\footnotetext{
${ }^{6}$ Quoted by Himmelfarb 1991, p. 93.

${ }^{7}$ See Booth 1892.
} 
produced a social class analysis of the people of York based on observations and judgements about "obvious want or squalor" or "secondary poverty", but this could not be reconciled with his income-based analysis. ${ }^{8}$ By 1941, Rowntree had abandoned the concept of secondary poverty, and the primary poverty line based on a minimum diet took on a life of its own (Glennister 2004: 26). Today this kind of incongruence is most evident between disciplines. Many economists of poverty tend to operate as if the poor could be defined exclusively with reference to a criterion level of consumption or income, and sociologists (and others) often operate as if income and consumption surveys were redundant and all that was needed to identify the poor was oral testimony and qualitative information collected by participant observation. ${ }^{9}$ This specialisation in partial approaches to estimating the incidence of poverty has been accompanied by a loss of overall perspective, and particularly a loss of connection with the motivation for poverty research, and the reasons for being concerned about the fate of the poor.

Economists may take it for granted that it is useful to discover that $\mathrm{x}$ per cent of the population of country $\mathrm{Y}$ are income or consumption poor, although the use to which their estimate is put falls in someone else's problem area. The government of country Y may be very keen to employ economists to make such an estimate, not because it is essential for devising anti-poverty policies, but because it wants to prove that the figure has fallen or is lower than in country Z. In this collection, Francis Teal's paper performs two useful functions in this context. It both clarifies the reason for regarding measures of

\footnotetext{
${ }^{8}$ See the fuller discussion of this problem in Himmelfarb (1991: 171-3).

${ }^{9}$ Bourdieu's (1999) study of 'social suffering' in France provides a classic example: Of the 629 pages in the text 565 are direct transcripts of interviews and little attempt is made to indicate levels of income or the specific forms of consumption deprivation that interviewees experience.
} 
consumption as measures of welfare (essentially because increases in consumption indicate increases in choice), and explains why average measures of consumption are widely distrusted. Using data from Ghana in the 1990s, he shows that while average measures show a decline in poverty, the poorest households headed by farmers experienced falls in their welfare. He concludes that a decrease in poverty - measured in the standard way - does not at all imply that most people in the economy had greater opportunities. This is a valuable antidote to a superficial reading of the income or consumption poverty line studies that economists produce. ${ }^{10}$

The current situation provides many professional incentives to stay within disciplinary confines. This has had the effect of reinforcing the fissiparous and centrifugal tendencies in poverty analysis. In 1970, Lipton (1970: p.11) remarked: "the lack of professional prestige in [interdisciplinary development studies] is self-confirming". Since then, unfortunately, the mechanisms that regulate professional prestige have created even more incentives not to stray across subject boundaries, especially within economics. Professional standards are maintained by a peer review that is almost exclusively from within the social science subject. University evaluation, and linked funding of research, again depends on peer review within one subject. People undertaking social science research are nowadays required to be in an academic institution, so they are all engaged in pursuing an academic career, progress in which again depends heavily on single subject peer review. In the UK they are brigaded into 'units of assessment' that have little

\footnotetext{
${ }^{10}$ Insert example of this: Dollar and Kraay.
} 
motivation to encourage them to explore across subject boundaries and they fear the loss of resources that such encouragement would entail ${ }^{11}$.

\section{The Resort to Intellectual Stereotyping}

Unfortunately, as the incentives for collaboration across subject boundaries are weakened, so the potential for mutual misunderstanding and ill-informed mutual criticism by researchers in different subject areas increases. Much of this is conducted at the individual and anecdotal level, by quoting examples of 'obviously wrong' statements made by those outside of one's own discipline. This will not do. Because the logic of disciplines is normative - i.e. it maintains standards advising researchers what they ought to do - the critique of disciplines cannot proceed merely by noting that some researchers in a particular discipline have said something absurd. Actual research is often 'undisciplined', and, while to point that out is a valid criticism of the researcher, it is not a valid criticism of the discipline. The critique of a discipline, if it is to succeed, must show that the intellectual procedures that researchers in it are expected to follow are absurd. This is always a harder case to prove.

Ideologies of disciplinary rivalry provide the currency for a debate in which selfjustification is a stronger motive than the search for understanding. Examples of such disciplinary ideologies are many and various, but perhaps most familiar are dichotomies

\footnotetext{
${ }^{11}$ In the 2001 UK research assessment exercise (RAE) groups who submitted to the development studies sub unit of assessment received grades well below the average for social sciences. No group received a grading above 4 indicating that none of them had reached 'international' standing for their research. Many groups believed that they had been 'punished' for not submitting to single discipline panels.
} 
that are put into service as stereotypes of entire social science disciplines. Example of such dichotomies include: objective versus subjective; quantitative versus qualitative; positivist versus post-positivist; and, generalised versus contextualised. ${ }^{12}$ In a further simplification, the terms 'objective', 'quantitative', 'positivist' and 'generalised' are assigned by the stereotype to the whole subject area of economics. By contrast, their opposites are assigned to the other social science subjects. ${ }^{13}$ While many SAPG researchers see 'subjective', 'qualitative', 'post positivist' and 'contextualised' as noble banners to carry (and few would find them objectionable), for economists, scientists and many policymakers these terms signal 'soft' social science that produces unreliable, anecdotal, and sometimes incomprehensible, accounts of what is happening. Are such stereotypes justified or are they merely unhelpful representations?

Taking the objective-subjective dichotomy as an example, it is not the case that there is a difference between economics and other disciplines in what it is that they analyse, or that economics focuses on concrete phenomena (incomes, exports) while sociology and anthropology study intangible things like beliefs and feelings. Economics, at least in its marginal utility version, is based on the analysis of preferences. It is true that some economists, starting with Robbins and Hicks in the 1930s, pioneered an "objectivist" shortcut for the purposes of demand theory, arguing that the choices people actually make provide all the information necessary to establish the utility of outcomes. ${ }^{14}$ This move

\footnotetext{
${ }^{12}$ Abbott (2001) argues that the 'chaos of disciplines' can be understood as fractal distinctions - these are dichotomies in which each dichotomy then fractures into a further dichotomy. This may provide a framework for a more detailed interrogation of the dichotomies listed here than we have space to provide. ${ }^{13}$ Lipton 1970; Hill 1986; Bardhan 1989; Harriss 2002; Kanbur 2002; Jackson 2002; White 2002; Ruttan 2001.

${ }^{14}$ The formalisation of the revealed preference approach in demand theory is attributable to Paul Samuelson (1948: 107-17).
} 
was dictated by a belief that subjective experience was unobservable, and that the use of reports on it was therefore methodologically problematic. This was a wrong turning, and by the 1970s, economists who, like Lipton, were dissatisfied with this exercise in reductionism, looked to psychology to supply the missing information on the actual motivations of the rural poor.

Since 1970, reliance on the axiomatic revealed preference approach has been challenged by a growing number of economists, who have explored what can be done with data on "reported subjective well being". ${ }^{15}$ Concerns about what surveys of such data really tell us remain, but now they are being actively explored rather than being taken as a reason for research passivity. These explorations are opening up a somewhat different avenue of cooperative work between economics and psychology. Psychologists know how to tackle the question of whether, for example, people's reports of their state of happiness are systematically influenced by their personality traits. This and related questions have to be resolved before the relation of reported subjective well being to economic indicators can be done in a properly critical manner.

To the extent that this proves to be possible, the exciting new, cross-disciplinary field of the economic and other determinants of happiness is opened up for further research. Some of the perennial questions of well being studies - under the rubric of poverty, inequality and the quality of life - will then have to be re-examined. At present, this research suggests that, on the one hand, subjective well being depends ceteris paribus on

\footnotetext{
${ }^{15}$ An early example was Tibor Scitovsky's 1973 lecture on “The Place of Economic Welfare in Human Welfare", Scitovsky 1986: 13-25.
} 
one's position in the hierarchy of income levels, but that increases in income do not increase well being pro tanto. Kingdon and Knight (in this volume) argue that subjective well being can be viewed as an encompassing concept that allows the importance of other variables such as income, basic needs, relative position and security to be evaluated. Their originality is to extend this general line of research by investigating this issue in developing countries. Using South African data, they show that factors such as education, employment, health and personal security all enter, along with income, into subjective well being. They warn that researchers who adhere to the income approach to poverty run the risk of over-simplifying what is at issue.

In terms of cross-discipline research, the economics and happiness theme opens an opportunity for economists to learn from sociologists about the formation of economic aspirations. If it turns out that it is the fulfilment of a range of economic and social aspirations that makes people happy, what is it that shapes aspirations? How do variations between countries in social mobility affect the way in which income aspirations play into assessments of subjective well being? Are there significant differences between the income aspirations of those living in rich and poor countries? Here is further fertile ground for disciplinary cooperation in poverty research.

To label economics as a quantitative discipline and other social sciences as qualitative disciplines lacks any fundamental justification. It seems plausible only because people confuse "quantitative" with "mathematical". If by "quantity" we mean a determinate amount, a sum that has been counted or measured, a quantitative discipline is one that 
makes use of empirical statistical data. There is nothing about the subject of economics that makes research into it uniquely well suited to using the methods of statistical inference ${ }^{16}$. Economics is not intrinsically more amenable (or less, as many famous economists have argued!) to statistical treatment than politics or sociology or even history. It is worth noting that

"The development of statistical thinking was a truly interdisciplinary phenomenon for which mathematics had no priority of position; new ideas and approaches arose as a result of the application of techniques borrowed from one or more disciplines to the very different subject matter of another" (Porter 1986:8).

The urge to co-opt statisticians to the cause of research was driven by the pursuit of objectivity, and the desire to achieve empirical results that are inter-subjectively testable, and tested. That pursuit and that desire can be an aim of any knowledge community or intellectual discipline. Indeed, the decision of very different knowledge communities to co-opt statisticians is perhaps the principal cause of the growing affinities across social science subjects.

The pursuit of objectivity does not, however, require an exclusively quantitative approach. Because of the cost of surveying large numbers of households and firms, questioning in this mode will be both researcher-determined and limited in depth. David Lawson and Andy McKay's paper (in this volume) shows how quantitative and

\footnotetext{
${ }^{16}$ But note that while anthropology and 'qualitative' sociology sometimes use numerical information they commonly prioritise non-numerical information that does not lend itself to statistical inference and which requires a separate process of numerical transformation, such as scaling or counting, if it is to be subjected to numerical scrutiny.
} 
qualitative approaches to the persistence of poverty in Uganda can be complementary. Participatory appraisal inevitably takes a more holistic view and can bring to the surface specific determinants of the persistence of poverty that are unanticipated by the researcher. The importance of excess alcohol consumption, domestic violence and personal insecurity has been brought to the surface by these techniques. These can be complementary with quantitative results, and enrich the causal story that emerges from the statistical analysis of survey data ${ }^{17}$.

Jocelyn de Jong's paper (in this volume) contributes further to this theme. It shows the limitations of a purely statistical approach to women's reproductive health in developing countries. Morbidity associated with poor reproductive health is increasingly recognised as an important diminution of women's well being, markedly more so than in the case of men. Yet using the disability adjusted life years (DALY) method of accounting for morbidity misses important effects on well being, such as the social stigma or social approval that is associated with conditions like female circumcision, pregnancy and labour complications. However, these effects can be gauged through anthropological methods. The relevance of this paper to the study of HIV/AIDS need not be underlined.

When examining the qualitative/ quantitative 'divide' it is important to note similarities and differences between the evolution of the social sciences in Europe and North America. Economics and anthropology in the two regions have tended to follow similar paths. Economics in both Europe and North America has become increasingly

\footnotetext{
${ }^{17}$ Also see McGee (2004) for a detailed examination of the complementarity of statistical surveys and participatory poverty assessments in Uganda.
} 
mathematical and/or based on the manipulation of large, quantitative datasets. ${ }^{18}$ At the same time, rational choice theory in its many varieties has increasingly provided the analytical framework for the research of economists. Similarly, anthropology in both regions focuses on the application of the ethnographic method to examine the understandings that people have of the social and physical worlds and has been influenced by post-modernism. In marked contrast, sociology and political science in Europe have diverged from North America. While in Europe the disciplines have increasingly focused on qualitative data and shifted towards critical realism and postmodernism, in North America the disciplines have become more positivist, more guided by rational actor models and/or more inclined to analyse large quantitative datasets. ${ }^{19}$

The dichotomy between positivist and post-positivist orientations, at least in Europe, does have considerable substance and has made cross-disciplinary work more difficult. Economists have largely avoided engagement with critical realist and/or post modernist analytical frameworks. The critical realism of Tony Lawson and his associates is an exception that proves the rule, because few mainstream economists engage constructively with his work. For other social scientists, the disciplinary drift has been away from positivism and has focused on whether to align with critical realist/interpretive approaches or to commit to a full-blooded, eclectic post modernism. An important component of these shifts is that, while SAPG researchers have increasingly highlighted the importance of context to effects (Sayer 2000: 15), economists tend to assume that

\footnotetext{
${ }^{18}$ See the next paragraph for a discussion of the 'super-positivism' that is driving much economic research.

${ }^{19}$ For a startling contrast see Sociologia Ruralis, the Journal of the European Society for Rural Sociology and Rural Sociology, the Journal of the (North American) Rural Sociology Society. While the journals focus on similar issues, their approaches and preferred methodologies are very different.
} 
contexts are similar, unless there is some specific reason to believe otherwise. ${ }^{20}$ While positivist economists and critical realist SAPG researchers may be able to converse and even learn from each other, at the extremes of ontological positions - super positivism and post modernism in the style of Jacques Derrida - communication is very difficult and the likelihood of descent into mutual disparagement very high.

Post-modernism à la Derrida maintains that the truth content of no discourse may be privileged relative to that of any other. Its scepticism leads to a radically relativist account of truth. Yet if the $t u$ quoque argument is applied, there can be no compelling reason to believe Derrida's own discourse. As a result, the Derrida version of postmodernism implodes by self-contradiction. Super-positivism, on the other hand, derives from a simplified model of 'science', taken over rather unthinkingly from what is supposed to be true of research in the natural sciences. Without entering further into the epistemological debate on the differences between natural and social science, it is sufficient to note the Duhem-Quine thesis, that what would count as falsification of a given proposition depends on some other beliefs that the researcher accepts as true, but without testing them. As a result, it is hard to argue that individual statistical tests can provide definitive evidence of the falsity or otherwise of hypotheses. This does not imply that such testing should be abandoned. It remains a valuable way of developing logically different 'webs of belief', and disciplining the competition for credence between them (Bevir 1999). The point here is that the rhetoric of science should not be used to drive a

\footnotetext{
${ }^{20}$ This was one of Polly Hill's (1986) most trenchant criticisms in her classic attack on development economics, Development Economics on Trial.
} 
wedge between economics and other social science subjects, with the claim that it is - or is capable of becoming - more 'scientific' than they are.

\section{Knowledge Communities and Intellectual Disciplines}

For the natural scientists, the standard view is that they form a single "republic of science" stretching from astronomy to medicine, and all subject to the authority of "scientific opinion" (Polanyi 1962: 59). For such a unified republic, the problem of cross-discipline work does not really arise. For social scientists, people studying other people, the issues of intention and meaning are never absent, and differences in methods of researching them strongly divide "social scientific opinion" in a way that complicates cross-discipline work.

There is an additional problem. Discussion of cross-discipline research in social science is often conducted on the assumption that the social science subjects in which we are interested - economics, sociology, anthropology and so on - should be treated as if each were a separate intellectual discipline. This assumes that each subject constitutes a unitary intellectual endeavour, clearly bounded, and distinguishable by differences in characteristics across a number of common criteria from all the others. Unfortunately for the simplicity of analysis, this is not true of social science subjects. We have to preserve a clear distinction between a social science subject and a social science discipline. 
The organisation of subjects in the social sciences is not the result of any clear or logical division of intellectual labour. Rather it is the outcome of complex historical processes. Abbott (2001:122ff) argues that social science subjects, as we recognise them today, largely evolved in the United States, as 'social structures' inside universities and as a mechanism across universities to manage the labour market for faculty. The organisation of academics in other countries (England, France, Germany) went through quite different histories (ibid). Over time, however, the US model has spread globally, so that now '...we find economics, political science, sociology, anthropology, history... and psychology' as a common core of social sciences (ibid: 125).

There are three main reasons why a strategy of taking the conventional list of core social science subjects as co-extensive with intellectual disciplines comes to grief.

(i) Unlike in the natural sciences, in social science the subject areas have different 'axes of cohesion'. '[I]n the social sciences... axes of cohesion are not aligned... anthropology is largely organised around a method, political science around a type of relationship, and economics around a theory of action. Sociology - best conceived as organised around an archipelago of particular subject matters - presents yet another axis of cohesion. These axes do not fall in any hierarchical order, a fact that has made interdisciplinarity in the social sciences more complicated than the simpler, linear interpretation of the natural sciences' (ibid: 140). 
(ii) There is thus considerable intellectual diversity within subjects (as well as differences in levels of intellectual diversity between subjects) ${ }^{21}$. This has important consequences, with some subjects (such as economics) having a relatively high level of intra-subject cohesion, while others (such as sociology) have much less. Some sociologists indeed seem to have greater intellectual affinity with researchers 'outside' their subject area than with others inside it. ${ }^{22}$

(iii) Whereas social science subjects do evolve over time, (e.g. sociology barely existed before the 1930s), they do so relative slowly. By contrast, the composition of intellectual activity within a subject changes relatively rapidly (e.g. in economics over the last twenty years, agricultural economics and neo-Marxist economics have both waned, while mathematical modelling and econometrics have flourished). Looking only at the evolution of core social science subjects often conceals the fate of intellectual disciplines.

In order to understand the diversity within and between subjects, we need to invoke social network theory, and specifically the idea of 'knowledge communities', sometimes

\footnotetext{
${ }^{21}$ This can be illustrated by the comments that leading figures make about their disciplines in the same highly reputed, crossdisciplinary encyclopaedia: ' ... an important achievement of economics has been its internal intellectual coherence'; '...it is questionable whether there remains any coherence in the term anthropology at all'; '... a pervasive dissatisfaction with the continuing divisions and fragmentation [in sociology]...it remains an open question whether a more unified and intellectually coherent discipline will eventually emerge'; ' ...political science has still not acquired fully independent status [as a discipline] in many parts of the world' (Outhwaite and Bottomore 1992: 20,184, 483 and 636).

${ }^{22}$ As an illustration, positivist and critical realist sociologists working (in the same department) on social capital and poverty may find they rarely communicate. The positivists may, however, find their work is closely related to econometricians researching social networks, while the critical realists will find a close affinity to researchers within human geography (see Sayer 2000:106-07) for a discussion of the latter).
} 
also known as 'epistemic communities'. A knowledge community is defined here as a network of knowledge-based experts who share an interest in a subset of knowledge issues, and who accept common procedural protocols as criteria to judge the success of their knowledge creation activities. What is essential here is not that all members of a knowledge community know or communicate with each other, but that they have common intellectual interests and aims, and a shared understanding and acceptance of the methods by which their sort of knowledge is successfully created. (This is in contrast with the definition used by Haas (1992: 1-37), who stresses shared faith in the application of knowledge to policy, thus allowing an epistemic community to encompass members from a variety of disciplines.) In our definition, the legitimate methods or 'procedural protocols' of each knowledge community provides it with its intellectual discipline, determining among other things the content of the training thought to be appropriate for those aspiring to become members.

However, in the social sciences, actual knowledge communities (in the above sense) correspond highly imperfectly with the boundaries of the core social science subjects, also confusingly often called 'disciplines'. For example, Sam Hickey's paper (this volume) is arresting precisely because it challenges the idea that political studies constitutes a single discipline, highlighting the divide between political science and political sociology as contrasting knowledge communities within political studies. He further argues that political sociology will provide the greater insights into the condition of the poor because its concern with the social bases of power makes it cross-disciplinary from the outset. Thus, within each social science subject are varying numbers of 
knowledge communities, with different intellectual orientations and norms, that bind them more or less closely to their subject area and which shape the degree of affinity they have with knowledge communities outside their subject boundary. For example, there are strong methodological and conceptual parallels in the analysis of poverty as between micro-economists, political scientists using rational choice theory and quantitative sociologists. By contrast, there is a chasm between applied micro-economists using advanced econometrics and economists pursuing the old institutionalist research programme.

Cross-disciplinary work on poverty and well-being in the social sciences, as in all other fields, involves the active extension of two or more knowledge communities' networks, and the making of a link or junction between them. Junction may provoke some adjustment or widening of the common interests of both communities, but it may also challenge the accepted 'procedural protocols' with which both currently work. Such protocols are not necessarily incommensurable, they are currently often incommensurate, and the way to making them common is not yet clear. The resulting potential for normative dissonance inevitably raises the question of the different forms that successful cross-disciplinary work can take.

Cross-disciplinary research can be seen as having two main variants: interdisciplinary and multidisciplinary approaches. Although the terms are used interchangeably by many people, we suggest that they are not the same, and that there is a valid distinction to be made, one that is more than just a minor quibble. The term 'interdisciplinary' is the 
older, dating from the 1920s. It was used then mainly in the context of the natural sciences, although the idea also affected the social sciences. The US Social Science Research Council was actually founded at that time to 'deal only with such problems as involve two or more disciplines'. ${ }^{23}$ Interdisciplinary research often implied a belief that those who practised it could create new research fields as a result. This promise was more likely to be fulfilled in the natural sciences than in the social sciences, for the reason already explained - the different axes of cohesion in the latter. The term was slow to gain currency, and it was only from the 1960 s that it began to make much impact. ${ }^{24}$

Michael Lipton (1970) advocated 'interdisciplinary development studies', and the adjective 'interdisciplinary' has been the one that has tended to persist in the vocabulary of social science research funding bodies. The precise formulation that Lipton gave to the term 'interdisciplinary' has been largely forgotten in the intervening years. Ravi Kanbur (2002) has recently sought to define the terms "a little more precisely to indicate different types of mixing of disciplines". We shall follow his definitions, so that:

- Crossdisciplinarity is a generic term referring to any analysis or policy recommendation based substantively on analysis and methods of more than one discipline.

\footnotetext{
${ }^{23}$ Evans, 2003, p.10, citing Charles Merriam in the American Political Science Review, Vol. 20, (1926), p. 186.

${ }^{24}$ Historically, development studies has played a major role within Anglophone social sciences in promoting crossdisciplinary research. Abbott (2001: 133) observes that ' $[\mathrm{t}$ ] he 1960s, by contrast [to earlier decades] proved an interdisciplinary bonanza, as the modernization paradigm swept development studies in anthropology, sociology, economics and political science. Enormous multidisciplinary teams took on major problems... population, area studies, agriculture, development.'
} 
- Interdisciplinarity refers to research that attempts a deep integration of two or more disciplinary approaches from the beginning and throughout an entire research exercise. $^{25}$

- Multidisciplinarity refers to work in which individual discipline-based researchers (or teams) do their best, within their disciplinary confines, to examine an issue and subsequently collaborate to develop together an overall analytical synthesis and conclusions (Kanbur, 2002: 483).

We should note, however, that there are a variety of ways in which mixes of interdisciplinarity and multidisciplinarity might be combined.

Cross-disciplinary research has been advocated in a variety of contexts. At the practical level, a developmental task, such as strengthening food security, planning new towns or increasing female school enrolment, is often said to require the cooperation of specialists from different disciplines, and we regard it as uncontroversial. At the academic level, it has been argued at least since the 1940s that a fuller understanding of social phenomena requires the cooperation of specialists in different intellectual disciplines, making use of the light that each can throw on the others' analyses. ${ }^{26}$ This could involve either multidisciplinary or interdisciplinary approaches.

The concept of 'multidiscipline research' emphasises that individual researchers (or teams) should continue to conduct research within the discipline or disciplines in which

\footnotetext{
${ }^{25}$ This might be through an individual who personally integrates disciplinary perspectives and methods or by a team (two or more) people coming from different disciplines and producing a unified design for research.

${ }^{26}$ See, for example, Julian Huxley's discussion of the social sciences in UNESCO: Its Purpose and its Philosophy, Paris, UNESCO, 1946, p. 44-7.
} 
they have been trained. Kanbur's definition of multidiscipline research also usefully emphasises that polymath abilities in individuals, or the learning of a second discipline in which one is as expert as in the first, are not pre-conditions of such research - as Streeten once $\operatorname{argued}^{27}$. While some have mastered a second discipline (Amartya Sen, ${ }^{28}$ for example, moved with ease from economics into philosophy) others have been less successful in the attempt. ${ }^{29}$ The alternative is by coordination within a group of individuals. Whether it is best to pursue a polymath or group approach will depend on the human and financial resources available, the time scale for any specific piece of research and the preferences of researchers.

Some might object that the concept of 'multidiscipline research' gives excessive credence to the intellectual virtue of 'disciplines'. "What is a discipline", they might ask, "that its preservation should be so important?" Others might respond that every discipline has its specific logic, which is a set of norms of reasoning appropriate to the subject matter being analysed. $^{30}$ This normative logic has to be learned, and hopefully improved, by each new generation of researchers in the discipline. The normative logic of disciplines can thus be thought of as accumulated distillations of long traditions of enquiry. Crossdisciplinary research would be suspected of lack of rigour if its practice required participants to abandon conceptual and methodological standards that their knowledge

\footnotetext{
${ }^{27}$ Paul Streeten (1974:26) claimed that "the only forum where interdisciplinary studies in depth can be conducted successfully is under one skull."

${ }^{28}$ Sen holds positions as Professor of Economics and Professor of Philosophy at Harvard along with other positions.

${ }^{29}$ Lipton (1970, p. 11) cited the case of Everett Hagen, when remarking that "attempts by first-rate [single discipline] specialists to work in other disciplines ... often produce results that are not highly regarded by the new discipline and not understood in the old".

${ }^{30}$ See Bevir 1999, p. 8-9.
} 
communities had previously regarded as essential. Multidisciplinary research does not take that risk.

By contrast, interdisciplinary research is relatively more challenging to social scientists and is likely to take them out of their intellectual comfort zones. It requires that an individual (or more likely a group drawn from two or more disciplines) seek to integrate the concepts and methodologies of different disciplines from the outset of a research project. This is demanding (intellectually and in terms of finance and researcher time), as each discipline has to learn about the logic of other disciplines and to strive to integrate these logics without compromising the standards of rigour of its own discipline. For some pairings of knowledge communities, for example econometrics and critical realist sociology, this may be impossible as the 'rigour' of each group is seen as fundamentally flawed by the other. While cross-disciplinary criticism can sharpen work it is unlikely to be something that can be built on, if the criticisms are that a collaborator, who is respected within his/her discipline, has produced 'nonsense'.

Fortunately, successful examples of interdisciplinary poverty research are emerging, as illustrated by the work of Adato, Carter and May (2004). In this example, econometrics and sociological life histories are rigorously combined. The econometrics yields statistically representative findings about the correlates and characteristics of poverty dynamics. Then, using the survey results as a sampling frame, sociological life histories provide deep accounts of the processes that are associated with falling into, climbing out 
of and being trapped in poverty for a subset of households whose position within the larger population is known.

\section{The Fallacy of Intellectual Territory}

Apart from stereotypes of disciplinary rivalry, another persistent obstacle to crossdiscipline research has been a discipline-based territoriality about subject matter. It is often (wrongly) assumed that certain subjects belong within the boundaries of specific disciplines. Anthropologists were thought to have a prior claim to the family and the tribe, sociologists to religions and trade unions, political scientists to governments and elections and economists to money and the market. Therefore, when a researcher in one discipline investigated a subject that was 'beyond his intellectual jurisdiction' something academically improper was thought to have occurred. Researchers who committed this impropriety even paid tribute to the prevailing view by speaking of their activity as 'trespassing'.

This territorial view of the subject matter of knowledge has led to economists being accused of intellectual 'imperialism' for their recent willingness to apply economic logic to realms of enquiry that have not been conventionally viewed as part of economics. For example, Jackson (2002: 497) writes of '.. an economic imperialism which colonises another discipline, rather than conversing with it'. Criticisms of such 'colonisation' are, on the whole, directed towards economists from SAPG researchers. In recent times these criticisms have focused less on defending a claimed subject matter than on

\footnotetext{
${ }^{31}$ For example, Hirschman 1981, p. v.
} 
opposing the intrusion of an alien analytic method. Particularly in the line of fire has been the application of '... methodologically individualist, choice-based economic theory...' (Harriss 2002: 488) to issues such as social capital.

Marcel Fafchamps' paper (in this volume) on social capital responds to this charge. $\mathrm{He}$ defends economists' preoccupation with individual rationality and choice by reference to the type of policy recommendations that this produces - policies for changing incentives, rather than for propaganda or compulsion. Moreover, his discussion of social capital is set firmly in the context of the theory of public goods and collective action. It stresses that, depending on the level of development of formal institutions, social capital can act either as their substitute or their complement. Fafchamps carefully points out some of the dangers of encouraging social capital to substitute for formal institutions, such as increased inequity and/or damage to generalised trust, and how these dangers might be minimised.

To put up 'no trespassing' signs in the face of arguments like these is surely misguided, as well as ineffective. From its start in the 1980 s, the social capital debate was intended to explore how economics and sociology could be brought together intellectually. Rather than denounce or disdain economists' studies of personal and group relations, a critical attempt to build on their insights is required. Which have been fruitful, which unfruitful, and why? Criticism and counter-criticism across disciplines, rather than a blanket prohibition, seem to be called for here. ${ }^{32}$ The same is true in reverse. There are

\footnotetext{
${ }^{32}$ Cooperation within a cross-disciplinary research programme does not have to mean agreement amongst partners: it can be highly productive when a partner in one discipline puts time and effort into explaining to
} 
sociological and political aspects to subjects that may seem fundamentally economic, such as the operations of markets, the structure of the firm and the forms of economic contracts. Forays in the reverse direction are well established in the sociology, social psychology and social anthropology of economic life, and have proved fruitful fields of study. There is every reason why they should be encouraged rather than discouraged. The junction of sociology and economics can be approached from two directions.

If there is no territoriality of subjects in social science, how are the boundaries of social science disciplines constituted, and why does the need to go beyond them arise? Lipton's (1970) answer was that the cultural and institutional context of developed industrial countries had been decisive in the formation of the dividing lines, which he claimed corresponded "to the division of variables into sets that can safely be treated as "nearly independent"" in that rich country context. This definition of boundaries then provided him with the justification for research outside them. In the actual cultural and institutional context of rural poverty in poor countries, near-independence does not hold; in this different reality, the conventional sets of disciplinary variables are much more interdependent, and thus need to be studied together if their analysis is to make sense.

Today the Lipton notion of social science disciplines as sets of variables that are strongly correlated among themselves, but not with other sets, in a given social context, may seem less than fully convincing. We have suggested that disciplines are not just bundles of variables that it is useful to think about together. They are also different ways of

someone from another discipline their precise criticisms of the concepts, assumptions and methods that have been utilised. 
thinking about 'variables' - different conceptions of what is the problem with them and different conceptions of what would constitute a solution to it (e.g. causal explanation or understanding). A disciplinary paradigm comprehends an authoritative protocol of investigation, as well as its characteristic objects of thought. It has typical problematics, axioms, and assumptions, and approved procedures of successful investigation. It is this conceptual logic that helps researchers to select out of the myriad of possibilities the variables whose co-variation - or lack of it - is of interest, and to tell them what interpretation they may give to their results.

Granting that disciplines have distinctive conceptual logics, as well as differences in the variables of analysis, does not weaken the case for cross-discipline research. Rather, it strengthens it. The earlier approach could be seen as a summons by economists to other social scientists to bring them some new and exotic variables to be fitted into their equations and subjected to their idea of rigorous testing. This is a summons that other social scientists are often - perhaps not so very surprisingly - reluctant to obey. Lipton himself, despite deploring the arrogance of economists, might even be read in this sense by an unkind critic. $^{33}$ When it is granted that all disciplines are seeing the same phenomena - that there is an underlying reality, human behaviour, but that it is being looked at through different lenses, focussed differently - does it not become more interesting, for the purposes of one's own research, to know what it is that the others are seeing?

\footnotetext{
33 "To be brutal, economists are forced by the realities to seek to impose their own quantitative and testable hypotheses ... so long as other [disciplines] do not put such hypotheses forward", Lipton 1970, p. 12.
} 
Wendy Olsen's paper (in this volume) argues strongly that it does. Using the example of the debate on land tenancy in India as her example, she makes a strong plea for greater resort to methodological and theoretical pluralism. She sees the placing together of theories that are at odds with each other as a source of intellectual tension, and that tension as a source of creativity, both conceptual and metrical. Recognising from the Duhem-Quine paradox that a pure falsification strategy is incomplete, she advocates the use of additional criteria of truth under the banner of "scientific realism".

\section{Disciplines and Practising Professions}

Michel Foucault's work has emphasised the links between knowledge creation and power, explaining how that process supports patterns of domination. ${ }^{34}$ It is surprising, then, given the regularity with which commentators on development and poverty research have distinguished between what economists and other social scientists do, that hardly any literature points out that economics is very different as it is an officially recognised 'practising profession'. In most countries, including the UK and USA, governments recognise economists as a profession and recruit significant numbers of them into public service. While anthropologists, human geographers, political scientists and sociologists are recruited into public service this is to take on specific roles for which they are competent and not to join a professional cadre that is recognised across the public services. This difference has profound implications for the ways in which disciplinary based knowledge can influence public policy.

\footnotetext{
${ }^{34}$ See Mark Philp, "Michel Foucault" in Quentin Skinner (1985: 67-81).
} 
The professional status of economics means that academic and research economists have direct access to a cadre of like-minded and like-trained colleagues in government, in our example to economists engaged in the analysis of poverty and well-being. This creates a channel through which what is happening in the discipline (e.g. methodological individualism, choice based theory) is directly transmitted to the analytical frameworks and policy recommendations of key advisors to government.

The status of economics as a practising profession stands in stark contrast to the SAPG disciplines. Until relatively recently they had to rely on influencing public debates and policy through 'enlightenment' - letting their knowledge filter through to public agencies and policy makers through the media (lectures, books, newspaper commentaries) and NGOs - rather, than being able to transfer it directly through the 'engineering' approach that is available to economists and scientists (Hulme and Turner 1990). This situation has contributed to dividing economics from the other social sciences, and weakening the prospects for cross-disciplinary work, in two ways. Firstly, it has left SAPG researchers on the sidelines (in reality and/or in their perceptions), carping about economists (and, especially neo-classical economists) dominating analysis and policy. Second, it has meant that economists play a direct role in shaping the research agendas of development agencies and thus development studies. This has meant that they have (or are perceived to have) easier access to research funding as academic economists converse regularly with practising economists. The most obvious and important examples of this are the IMF and World Bank. The IMF's analyses rarely move outside of the neo-classical knowledge community, while at the World Bank 'research' often seems synonymous with 
'development economics'. Indeed, Clift (2002: 475) points out that the Bank-initiated Global Development Network (GDN) was 'dominated by the economics discipline'. In effect, the initial design of the GDN was basically as a global development economics network! Given the way in which multinational and bilateral agencies have influenced the academic agenda of development studies (and now poverty and poverty reduction), such a single subject orientation has profound implications for knowledge creation.

Maia Green's paper (in this volume) explores these implications. She emphasises that anthropological studies conducted outside the framework of "development" have consistently demonstrated the social constitution of categories and the importance of social relations as the bedrock of inequality. The anthropological perspective thus illumines the constitution of poverty, both as a category of development thinking and as a label applied to particular social categories. From this understanding, she draws out the role of the national and international development agencies in reifying and homogenising the concept of poverty and guiding its research priorities.

The recent emergence of the sub-professions of 'social development' and 'governance' may have begun to create mechanisms by which the SAPG disciplines can more easily relate the knowledge they create to public agencies. However, it would be quite incorrect to see these sub-professions as having the status of a practising profession, similar to economics. $^{35}$ Social development and governance are not recognised civil service professions in any country; the links between academic training, a specified disciplinary

\footnotetext{
${ }^{35}$ The UK's Department for International Development (DFID) has recently merged its social development and governance advisors into a single group that seems likely to function as issue specific 'generalist' policy advisors rather than the 'disciplined' professional role of economists.
} 
knowledge base and professional standing in these sub-professions is unclear; and, these sub-professions are largely based in multilateral and bilateral development agencies they barely exist in the public service in developing countries. For the foreseeable future, the status of economics as both a discipline and a practising profession seems likely to encourage economists to envision their contribution to the understanding of poverty and well-being as a mono-discipline, rather than a cross-discipline, activity.

\section{How to Gain the Benefits of Cross-discipline Research?}

How might it be possible, in a prevailing atmosphere of disciplinary inversion and rivalry, to bring about greater collaboration and fruitful cross-discipline social science research? An examination of the existing patterns of cross-disciplinary exchanges is an obvious starting point. In this we are assisted by recent analysis of the pattern of citation between economics and other disciplines. Twenty years ago, little such analysis had been attempted. Such work as there was seemed to show that economics drew little from any other social science discipline, but that it was drawn on modestly but significantly by political science and sociology (Rigney and Barnes 1980:114-127). Now a more extensive study of 42 economics and 20 'non-economics' journals has been conducted, and an analysis of disciplinary cross-citation for the years 1995-97 has been reported. In general, it does not contradict the findings of the earlier study. The picture of economics that emerges is as a discipline that "builds only slightly on knowledge from its sister disciplines" (anthropology, political science, psychology and sociology), and as one that is a "modest but significant source of scholarly knowledge for political science and 
sociology" (Pieters and Baumgartner 2002:504). Cross-citation between economics, anthropology and psychology was reported as nil.

This study cannot tell the whole story of cross-disciplinary communication. In the first place, it relates only to journal articles, and a selection of those. Books remain an important, though declining source of citations. Second, people cite for different reasons, and not always to refer to a source of knowledge that is regarded as valuable - often it is to criticise a high-profile but controversial author's work. Third, their citation behaviour also changes over time, so that the most influential contributors to a discipline tend to get taken for granted rather than cited (Stigler 1982:173-191). Having made these necessary caveats, it would still be an exaggeration to claim that much cross-disciplinary communication is taking place, or that no more could be achieved.

To look forward to greater cross-disciplinary cooperation might, in the face of this evidence, seem to be the triumph of hope over experience. Yet, if one were inclined to be hopeful, what would it be necessary to do? First, it is necessary to encourage groups or teams to take on such activity. While we also welcome 'renaissance people' with two or more disciplinary trainings it is unlikely that there are enough of them around to make a difference within the next few years. Out of such group work an essential ingredient for effective collaboration, 'mutual professional respect' (White 2002: 519), can be developed as researchers recognise that 'rigor is the proper application of techniques' (ibid: 512) and not something on which any discipline has a monopoly. 
Next, it is necessary to find agreement among a group of social scientists of different disciplines that there indeed are social problems of a multi-faceted character, which it is important to investigate, and to the investigation of which any one discipline cannot make a wholly conclusive contribution. There has to be a set of social phenomena that provide an agreed common ground. Fortunately, the awareness is gradually increasing that the study of poverty and well-being does provide such a common ground ${ }^{36}$. Economists may still use income and consumption measures of poverty and inequality extensively, but they recognise that 'non-monetary indicators' (Baulch and Masset 2003) and 'multidimensional' measures (Barrientos 2003) now have great relevance to their work. Recently SAPG researchers have begun to work more closely with economists on poverty research. And there are increasingly numerous examples of the contribution that crossdisciplinary research can make to the understanding of poverty on topics such as labour exchange, household economies of scale and child survival (White 2002). However, cross-disciplinarity has to be striven for. As Booth et al. (1999) point out, much of the proclaimed 'multidisciplinary' approach to national poverty assessments has been 'twin track'. The specialists concerned have focused on their own products and have rarely made the effort to try to synthesize findings or interrogate disparities.

Then there must be agreement that, if one discipline cannot provide a wholly conclusive contribution, it is worthwhile to monitor what is being done by other disciplines in this field, conceptually and empirically. This may be hard to achieve. At a minimum, the

\footnotetext{
${ }^{36}$ Most obviously in the UK through the support of the ESRC which has financed an interdisciplinary research centre (the Well-being and Development Research Centre, see www.welldev.org.uk ) and a multidisciplinary research centre (the Global Poverty Research Group, see www.gprg.org). DFID has also supported the crossdisciplinary (ie multidisciplinary and interdisciplinary) Chronic Poverty Research Centre (www.chronicpoverty.org).
} 
ideologies of disciplinary rivalry must be abandoned. However, even when they can be set aside, the individual researcher will see that monitoring other disciplines has a certain cost in time and uncertain benefits in intellectual stimulation and career development. As Lipton (1970:6) foresaw, such research is "expert-intensive, especially since yet more time is needed for inter-expert communication". At the start, therefore, there must be some way of breaking through this impasse, and regular group cross-discipline seminars could provide it. Yet there is nothing inevitable about success; thought processes will not be dragooned. It is individuals bent on the creation of knowledge through their personal efforts, supported and constrained by the social structures of disciplines, knowledge communities and professional practices, who must 'make the difference'.

One more hopeful inference can be drawn from today's clearer picture of crossdisciplinary communication. Lipton feared that the lack of professional prestige of cross-disciplinary studies would be self-confirming, but it is now possible to argue that this is not the case, at least as far as the central act of publication is concerned. It turns out that most of the existing cross-disciplinary communication (at least in terms of citing and being cited in journals) occurs through the top-ranking "core" journals of the economics profession. This is a disappointment for those of us who have devoted much effort to "peripheral" journals expressly designed for cross-disciplinary communication. However, it implies that those willing to look across disciplinary boundaries for their inspiration need not fear exclusion on those grounds from the most favoured journals of 
the economics profession. ${ }^{37}$ One often-mentioned disincentive for economists to engage across a broader scholarly range looks increasingly like a paper tiger.

How will the benefits of greater collaboration between disciplines make themselves felt? The changes in understanding that this collaboration - if successful - will bring are changes not only for those engaging in cross-disciplinary research but also for those who see themselves as working only within their own discipline. In other words, by attending to the poverty research of anthropologists, economists may produce more imaginative and searching economic analyses; by sharing the understandings of economists of poverty, political scientists or social psychologists may be led to new questions, or to better elaborated answers to old questions. The approach taken to cross-disciplinarity is likely to change over time as researchers get to know each other more. Initial crossdisciplinary contacts (seminars, meetings, critiques of each others work) can serve as a base to design multidisciplinary work from which systematic interdisciplinary may evolve over time.

Moreover, the overall effect of these changes will be away from cognitive dissonance, and towards a more integrated understanding of the phenomenon under investigation. One can decrease cognitive dissonance in other ways, too: it can be done by various reductionist moves, which lead cumulatively to the intellectual involution of disciplines.

\footnotetext{
${ }^{37}$ Similar data is not available for other social science disciplines, but one can argue that the 'high rating' placed on 'premier division' cross-disciplinary journals such as the Journal of Development Studies, World Development, Economic Development and Cultural Change, Economy and Society and Development and Change by the SAPG disciplines and economics in the UK's research assessment exercise augurs well for the future. In the UK the recent establishment of a development studies unit of assessment for the 2008 research assessment exercise (RAE), which allocates research income across departments, creates a potentially favourable context for cross-disciplinary work.
} 
Economists who argue for joint work with other disciplines are familiar with them and their use as blocking devices (Earl 1990:751). The razor attributed to William of Ockham is, however, an illogical paradigm of science; it can simply cut away the sources of future intellectual growth. Cross-disciplinarity may not always be the easiest path, but it is the way of the future for research on poverty, well-being and inequality. 


\section{References}

Abbott, A., 2001, Chaos of Disciplines, Chicago, University of Chicago Press.

Adato, M., Carter, M. and May, J. (2004), 'Sense and Sociability: Social Exclusion and Persistent Poverty in South Africa', BASIS background paper for the conference on Combating Persistent Poverty in Africa, 15-16 November, University of WisconsinMadison. Available online at http://www.basis.wisc.edu/persistentpoverty papers.html Bardhan, P., 1989, Conversations between Economists and Anthropologists, Delhi, OUP. Barrientos, A., 2003, 'What is the impact of non-contributory pensions on poverty? Estimates from Brazil and South Africa', CPRC Working Paper 33, Institute for Development Policy and Management, University of Manchester, UK. Available online at http://www.chronicpoverty.org/pdfs/Armando\%20BarrientosNo33.pdf

Baulch, B. and Masset, E. 2003, 'Do monetary and non-monetary indicators tell the same story about poverty? A study of Vietnam in the 1990s', World Development, 31(3), 441454.

Bevir, M., 1999, The Logic of the History of Ideas, Cambridge, Cambridge University Press.

Booth, C., 1892, Life and Labour of the People in London, London, Macmillan.

Booth, D., Leach, M. and Tierney, A., 1999, 'Experiencing Poverty in Africa: Perspectives from Anthropology', Background Paper 1(b) for the World Bank Poverty Status Report 1999. Washington D.C., World Bank.

Bourdieu, P. et al., 1999, The Weight of the World: Social Suffering in Contemporary Society, London, Polity Press. 
Clark, D. A. 2002a, Visions of Development: A Study of Human Values, Cheltenham: Edward Elgar.

Clark, D. A. 2002b, 'Development Ethics: A Research Agenda', International Journal of Social Economics, 29(11), 830-848.

Clift, C., 2002, 'Foreword to cross-disciplinarity in development research', World Development, 30(3), 475

Crocker, D. (1991), ‘Toward development ethics',World Development, 19 (5), 457-83.

Dollar, D. and Kraay, A. 2002, 'Growth if Good for the Poor', Development Research Group, World Bank. Forthcoming in the Journal of Economic Growth and available online at http://econ.worldbank.org/files/22015_Growth_is_Good_for_Poor.pdf

Earl, P. E., 1990, “Economics and Psychology: A Survey”, Economic Journal, Vol. 100, No. 402, p. $718-755$.

Evans, G. R., 2003, “The Scholarly Misfits”, Oxford Magazine, No. 211, p. 10-12.

Gasper, D., 2004, The Ethics of Development, Edinburgh: Edinburgh University Press.

Glennister, H., 2004, “The Context of Rowntree's Contribution”, in One Hundred Years of Poverty and Policy, York, Joseph Rowntree Foundation.

Goulet, D.A. 1971, The Cruel Choice: A New Concept in the Theory of Development, New York: Atheneum.

Goulet, D. A. 1985, Development Ethics: A Guide to Theory and Practice, London: Zed Books.

Griffin, J. 1986, Well-Being: Its Meaning, Measurement and Moral Importance, Oxford: Oxford University Press. 
Haas, P., 1992, "Introduction: epistemic communities and international policy coordination", International Organization, Vol. 46, No. 1, Winter.

Harriss, J., 2002, 'The case for cross-disciplinary approaches in international development', World Development, 30(3), 487-496.

Hill, P., 1986, Development Economics on Trial; the Anthropological Case for a Prosecution, Cambridge, CUP.

Himmelfarb, G., 1991, Poverty and Compassion. The Moral Imagination of the Late Victorians, New York, Vintage Books.

Hirschman, A. O., 1981, Essays in Trespassing. Economics to Politics and Beyond, Cambridge, Cambridge University Press.

Hulme, D., 2004, 'Thinking "Small" and the Understanding of Poverty: Maymance and Mofizul's Story', Journal of Human Development, 5(2), 161-176.

Hulme, D. and Turner, M., 1990, Sociology and Development: Theory, Policy and Practice, London, Harvester-Wheatsheaf.

Huxley, J. 1946, Outline of a Philosophy for UNESCO, Paris, UNESCO.

Jackson, C., 2002, 'Disciplining Gender?', World Development, (30(3), 497-510.

Kanbur, R., 2002, 'Economics, social science and development', World Development, $30(3), 477-486$.

Knight, J. B., 1991, "The Evolution of Development Economics" in V. N. Balasubramanyam and Sanjaya Lall (editors), Current Issues in Development Economics, Basingstoke, Macmillan Education Ltd, p. 10-22.

Lipton, M., 1970, "Interdisciplinary Studies in Less Developed Countries", Journal of Development Studies, Vol. 7, No. 1, p. 5-18. 
McGee, R., 2004, "Constructing Poverty Trends in Uganda: A Multidisciplinary Perspective", Development and Change, Vol.35, No.3, p.499-524.

Nussbaum, M. C. (2000), Women and Human Development: The Capabilities Approach, Cambridge: Cambridge University Press.

Outhwaite, W. and Bottomore, T., 1992, The Blackwell Dictionary of Twentieth Century Social Thought, Oxford, Blackwell.

Pieters R. and H. Baumgartner, 2002, "Who Talks to Whom? Intra- and Interdisciplinary Communication of Economics Journals", Journal of Economic Literature, Vol. XL, No. 2, p. 483-509.

Polanyi, M., 1962, "The Republic of Science: Its Political and Economic Theory", Minerva, Vol. 1, No. 1, p. 54-73.

Porter, T. M., 1986, The Rise of Statistical Thinking 1820-1900, Princeton, Princeton University Press.

Qizilbash, M. 1996, 'Capabilities, well-being and human development: a survey', Journal of Development Studies, 33(2), 143-62.

Rahnema, M., 1992, "Poverty", in W. Sachs (Ed), The Development Dictionary, London, Zed Books, p.158-176.

Ravallion, M., 2001, 'Can qualitative methods help quantitative poverty measurement', in Kanbur (Ed) Qual-Quant: Qualitative and Quantitative Poverty Appraisal. (See http://www.people.cornell.edu/pages/sk145/papers.htm).

Rigney P. and D. Barnes, 1980, "Patterns of Interdisciplinary Citation in the Social Sciences", Social Science Quarterly, Vol. 61, p. 114-27.

Rowntree, B. S., 1901, Poverty: a Study of Town Life, London, MacMillan. 
Ruttan, V., 2001, 'Imperialism and competition in anthropology, sociology, political science and economics: a perspective from development economics', Journal of SocioEconomics, 30, 15-29.

Samuelson, P. A., 1948, Foundations of Economic Analysis, Cambridge, Mass., Harvard University Press.

Sayer, A., 2000, Realism and Social Science, London, Sage.

Scitovsky, T., 1986, Human Desire and Economic Satisfaction, Brighton, Wheatsheaf Books Ltd.

Sen, A. K., 1984, "Poor, Relatively Speaking", in A. Sen, Resources, Values and Development, Oxford, Blackwell, p. 325-45.

Skinner, Q. (editor), 1985, The Return of Grand Theory in the Human Sciences, Cambridge, Cambridge University Press.

Stigler, G. J., 1982, The Economist as Preacher and Other Essays, Oxford, Basil Blackwell.

Streeten, P., 1974, "Some Problems in the Use and Transfer of an Intellectual Technology", The Social Sciences and Development, Washington DC, The World Bank, p. 3-54.

White, H., 2002, 'Combining quantitative and qualitative approaches in poverty analysis', World Development, 30(3), 511-522.

WHOQOL Group (1998), 'Development of the World Health Organization WHOQOLBREF Quality of Life Assessment', Psychological Medicine, 28, 551-558. 